\title{
Frequency of Carotid Atherosclerosis in Hepatitis C Virus Positive Patients
}

\author{
Nazish Yaqoob ${ }^{1}$, Aijaz Zeeshan Khan Chachar ${ }^{2}$
}

\author{
${ }^{1}$ Woman Medical Officer, Mian Mir Hospital, Lahore \\ ${ }^{2}$ Senior Registrar, Fatima Memorial Hospital, Shadman, Lahore
}

\begin{abstract}
Background and objectives: Carotid atherosclerosis is the second leading cause of mortality and a leading cause of major disability. Conventional risk factors like diabetes, hypertension, smoking and hyperlipidemia have been established to play pivotal role in the etiology of atherosclerosis. Besides these risk factors, inflammation due to infections is being considered as a possible cause of the disease. Among infectious agents Hepatitis $\mathrm{C}$ has been proposed to play a major role in the etiology of Carotid atherosclerosis. The Current study was conducted to see the frequency of carotid atherosclerosis in patients having hepatitis $\mathrm{C}$ virus (HCV) infection in our population. Objectives: To determine the frequency of carotid atherosclerosis in already diagnosed HCV positive patients. Study Design: Cross Sectional.Study Settings: The study was carried out in medical inpatient and outpatient departments of Sir Ganga Ram Hospital, Lahore. Study duration: Six months i.e from 28 April to 27 October 2016.Patients \& Methods: Three eighty three (383) patients were included in the study according to inclusion criteria and carefully applying exclusion criteria after inquiring detailed history and doing clinical examination. Data Collection Procedure: Demographics like name, age, gender \& address were noted. Patient's detailed history about HCV was asked and Carotid Doppler was performed by researcher \{using ultrasound machine APLIU TOSHIBA\}, and findings were confirmed by the senior consultant Radiologist of the hospital who had vast experience in dealing such kind of patients and then presence of carotid atherosclerosis in HCV positive patients was noted. All this information was taken on Performa. Results: Carotid atherosclerosis was present in 131(34.2\%), absent in $252(65.8 \%)$ patients and diabetes present in $246(64.2 \%)$ patients and absent in 137(35.8\%). Of 131 patients, $70(54 \%)$ were males and 61(46\%) females. 54(41\%) patients had hepatitis $\mathrm{C}$ for $<3$ years and $77(59 \%)$ for $\geq 3$ years. $93(71 \%)$ patients had positive family history of atherosclerosis while $38(29 \%)$ patients had none. Mean BMI of total patients was $29.64 \pm 6.64 ; 119(31.1 \%)$ patients of BMI $<25 \mathrm{~kg} / \mathrm{m}^{2}$ and $264(68.9 \%)$ with BMI $\geq 25 \mathrm{~kg} / \mathrm{m}^{2}$.out of these 131 patients; $105(80 \%)$ had age $<45$ years and $26(20 \%)$ had age of $\geq 45$ years. BMI was $<25 \mathrm{~kg} / \mathrm{m}^{2}$ in 30 $(23 \%)$ and $\geq 25 \mathrm{~kg} / \mathrm{m}^{2}$ in $101(77 \%)$ patients. Conclusion: HCV positive patients in significant numbers had carotid atherosclerosis which is quite alarming, early diagnosis and screening can reduce the morbidity and mortality related with carotid atherosclerosis.
\end{abstract}

Keywords: Enzyme linked Immune-Sorbant Assay ELISA, Hepatitis C, Carotid Atheroscelrosis

\section{Introduction:}

Hepatitis $\mathrm{C}$ is a global health problem. It is estimated that $2-3 \%$ (130-170 million) of the world's population is $\mathrm{HCV}$-infected. Prevalence of $\mathrm{HCV}$ infection is less than $2 \%$ in USA but higher (more than $2 \%$ ) in South Asia. ${ }^{1}$ Pakistan has the $2^{\text {nd }}$ highest prevalence of hepatitis C (4.5-8\%). ${ }^{2}$ Long term sequela of $\mathrm{HCV}$ include liver cirrhosis in every $5^{\text {th }}$ patient of $\mathrm{HCV}$, while $3-10 \%$ of cirrhotic patients eventually develop hepatocellular carcinoma. ${ }^{3}$ In addition to liver disease, $40-74 \%$ of patients develop at least one extrahepatic manifestation including mixed cryoglobulinemia, non Hodgkin lymphoma, porphyria cutanea tarda \& lichen planus \& atherosclerosis etc. ${ }^{4}$

Cerebrovascular disease is becoming a great health burden as it is $2^{\text {nd }}$ leading cause of mortality worldwide. ${ }^{5}$ Conventional risk factors for stroke like cigarette-smoking, Hypertension, Diabetes, Obesity,
Hyperlipidemia \& Alcohol consumption are unable to completely explain occurrence of disease \& new risk factors like infectious agents have been documented.HCV patients showed a higher level of inflammation \& accelerated atherosclerosis. ${ }^{6}$ The virus replicates in carotid plaques so $\mathrm{HCV}$ positive patients have a higher \& early risk of Stroke \& Coronary Artery Disease ${ }^{7}$ Chronic $\mathrm{HCV}$ infection increases the risk of ultrasonographically defined carotid plaques or carotid intima-media thickness which predispose to cerebrovascular disease. ${ }^{6,7}$ About 3-4 million people are infected per year, and more than 350,000 people die yearly from hepatitis Crelated diseases. During 2010 it is estimated that 16,000 people died from acute infections while 196,000 deaths occurred from liver cancer secondary to the infection. ${ }^{8,9}$ The total number of people with this infection is higher in some countries in Africa and Asia. Countries with particularly high 
rates of infection include Egypt (22\%), Pakistan $(4.8 \%)$ and China $(3.2 \%){ }^{10}$

Chronic HCV infection is associated with both hepatic and systemic inflammation, which is triggered by HCV either directly or indirectly. Such inflammatory pathways involve cytokines release and increased oxidative stress. HCV RNA sequences have been isolated within carotid plaques, supporting the hypothesis that HCV plays a direct proatherogenic role by inducing arterial inflammation, likely via the pro-inflammatory cytokine interleukin $1 \beta .^{11}$ In addition, HCV structural and non-structural proteins play a major role in initiating and maintaining chronic inflammation. HCV promotes an imbalanced $\mathrm{T}$ helper (Th)1/Th2 cytokines ratio perturbing the equilibrium between cellular immunity, promoted and maintained by interleukin (IL)-2, TNF- $\alpha$ and interferon- $\gamma$, and humoral immunity, sustained by IL-4, IL-5, IL-6 and IL-10. Compared to HCV negative individuals, patients with chronic HCV infection have been shown to exhibit higher TNF- $\alpha$ levels which are associated with an increased risk of heart failure and death. Moreover, an intermediate cardiovascular risk, higher levels of pro-inflammatory cytokines (IL- 6 and TNF- $\alpha$ ), and a higher ratio of pro-inflammatory/anti-inflammatory cytokines (TNF- $\alpha / \mathrm{IL}-10$ and IL-6/IL-10) have been reported in non-obese, non-diabetic, $\mathrm{HCV}$-infected patients than that observed in the control group. HCV-driven secretion of inflammatory cytokines may contribute to the development of cardiovascular disease through several effector mechanisms, including enhanced synthesis of matrix metalloproteinase-9, intracellular adhesion molecules, expression of anti-endothelium antibodies, and generation of oxidative stress and insulin resistance. ${ }^{12}$

Since Pakistan is an HCV- endemic area, the purpose of the study is to generate local data regarding prevalence of Carotid Atherosclerosis in Hepatitis C positive patients. Bearing in mind the non-invasive nature \& reliability of Carotid Doppler in detecting Carotid Atherosclerosis, as well as the high prevalence of the later in HCV positive patients, the aim of the study is early detection of Carotid Atherosclerosis for prevention of Cerebrovascular disease in HCV positive patients. This would ultimately lead to decrease in morbidity \& mortality in $\mathrm{HCV}$ positive patients \& decreases burden of health services. If a high prevalence of atherosclerosis is found then we can set up protocols screening of atherosclerosis in $\mathrm{HCV}$ patients

\section{Operational Definitions:}

Hepatitis C: Patient found "reactive" for Anti-HCV Antibodies by third generation ELISA for the last 6 months were considered to be Hepatitis $\mathrm{C}$ positive.
Carotid Atherosclerosis: Intima media thickness more than $0.8 \mathrm{~mm}$ as evident by carotid Doppler. It was assessed at the time of inclusion into the study

\section{Patients \& Methods}

Study Design: It was a cross-sectional survey.

Study Settings: The study was conducted in medical outdoor \& indoor of Sir Ganga Ram Hospital, Lahore.

Duration Of Study: The study was completed in 6 months i.e from $28^{\text {th }}$ April to $27^{\text {th }}$ October 2016

Sample Size: Sample size of 383 cases was calculated with $95 \%$ confidence level\& $5 \%$ margin of error by taking expected frequency of carotid atherosclerosis of $53 \%$ in $\mathrm{HCV}$ patients ${ }^{13}$

Sampling Technique: It was Non probability Consecutive sampling.

\section{Sample Selection:}

Inclusion Criteria:

- Age: $\geq 30-55$ years.

- Gender: Both males and females.

- HCV positive patients (as per operational definition) for at least 6 months.

\section{Exclusion Criteria:}

- Already diagnosed patients of Transient Ischemic Attack (TIA) \& stroke

- Diagnosed patients with hyperlipidemia, Total Cholestrol level of $>200 \mathrm{mg} / \mathrm{dl}$, Total triglycerides $>150 \mathrm{mg} / \mathrm{dl}$, low density lipoproteins LDL $>150 \mathrm{mg} / \mathrm{dl}$ and high density lipoproteins $\mathrm{HDL}<40 \mathrm{mg} / \mathrm{dl}$ (on history \& medical record)

Data Collection Procedure: After obtaining approval from the hospital's Ethical Committee, patients fulfilling the inclusion/exclusion criteria were enrolled after obtaining consent from Medical Outpatient Department of Sir Ganga Ram Hospital, Lahore. Demographics like name, age, gender \& address were noted. Patient's detailed history about $\mathrm{HCV}$ was asked and Carotid Doppler was performed by researcher \{using ultrasound machine APLIU TOSHIBA $\}$, the presence of carotid atherosclerosis in HCV positive patients was noted and was confirmed by the Senior Consultant Radiologist who had vast experiencing in dealing such kind of patients to avoid any errors in our findings.

Statistical Analysis: Data was entered and analyzed in SPSS version 25.0 Mean + standard deviation was calculated for quantitative variables like age. Frequencies and percentages were calculated for qualitative variables like gender and atherosclerosis. Stratification for age, gender, hypertension, family history of atherosclerosis, history of interferon treatment, duration of Hepatitis C, liver Cirrhosis (on ultrasound), Diabetes mellitus and body mass index (BMI) was done to control the effect modifier. Post stratification chi-square test was applied p-value of $\leq$ 0.05 was considered as significant. 
Frequency of Carotid Atherosclerosis in Hepatitis C Virus Positive Patients

Results: A total of 383 patients with Hepatitis C were included in study. Mean age of total patients in the study was 40.79 years with $\mathrm{SD} \pm 7.65$ years (table 1). There were total $280(74.67 \%)$ patients of age $<45$ years, and $103(25.33 \%)$ patients of age $\geq 45$ years (table 1)

There were $216(56.4 \%)$ males and 167 (43.6\%) females (table 1).The mean duration of patients infected with $\mathrm{HCV}$ was $3.58 \pm 1.83$ years (table 1). There were total 144(58.22\%) patients with HCV infection for $<3$ years duration, and 239(41.78\%) patients with $\mathrm{HCV}$ infection for $\geq 3$ years of duration (table 1).

Table 1: Distribution of age, gender and duration of Hepatitis C \& BMI of the study population.

\begin{tabular}{|l|l|l|}
\hline Age (Years & No of Patients & Percentage\% \\
\hline$<45$ years & 280 & 74.67 \\
\hline$\geq 45$ years & 103 & 25.33 \\
\hline Mean \pm SD & \multicolumn{2}{|c|}{$40.79 \pm 7.65$} \\
\hline Gender & \multicolumn{2}{|l|}{} \\
\hline Female & 167 & 43.6 \\
\hline Male & 216 & 56.4 \\
\hline Duration of Hepatitis C virus infection (years) \\
\hline$<3$ years & 144 & 58.22 \\
\hline$\geq 3$ years & 239 & 41.78 \\
\hline Mean \pm SD & $3.58 \pm 1.38$ \\
\hline BMI & \multicolumn{2}{|l|}{} \\
\hline$<25 \mathrm{~kg} / \mathrm{m}^{2}$ & 119 & 31.10 \\
\hline$\geq 25 \mathrm{~kg} / \mathrm{m}^{2}$ & 264 & 68.90 \\
\hline Mean \pm SD & $\mathbf{2 9 . 6 4} \pm \mathbf{6 . 6 4}$ \\
\hline Total & $\mathbf{3 8 3}(\mathbf{1 0 0})$ \\
\hline
\end{tabular}

Table 2: Distribution of Hypertension, liver cirrhosis, interferon treatment, family history of atherosclerosis, Carotid atherosclerosis and Diabetes mellitus status of the study population.

\begin{tabular}{|l|l|l|}
\hline Hypertension & No of Patients & Percentage\% \\
\hline Non Hypertensive & 219 & 57.18 \\
\hline Hypertensive & 164 & 42.82 \\
\hline Liver Cirrhosis & & \\
\hline Absent & 152 & 39.69 \\
\hline Present & 231 & 60.31 \\
\hline Interferon Treatment & & \\
\hline No & 256 & 66.84 \\
\hline Yes & 127 & 33.16 \\
\hline Family History of Atherosclerosis & & \\
\hline No & 216 & 56.40 \\
\hline Yes & 167 & 43.60 \\
\hline Carotid Atherosclerosis & & \\
\hline Yes & 131 & 34.20 \\
\hline No & 252 & 65.80 \\
\hline Diabetes Mellitus & & \\
\hline Absent & 137 & 35.80 \\
\hline Present & 246 & 64.20 \\
\hline Total & 383 & 100 \\
\hline
\end{tabular}

Table 3: Comparison of carotid atherosclerosis in both age groups/gender/duration/Hypertension status/ Liver cirrhosis status/family history of atherosclerosis/Interferon status/Diabetes mellitus status and BMI

\begin{tabular}{|c|c|c|c|c|}
\hline \multirow[t]{2}{*}{ Age } & \multicolumn{3}{|c|}{ Carotid Atherosclerosis } & \multirow[b]{2}{*}{ P-value } \\
\hline & Absent & Present & Total & \\
\hline$<45$ years & $175(62.5 \%)$ & $105(37.5 \%)$ & $280(73 \%)$ & \multirow[b]{2}{*}{0.025} \\
\hline$\geq 45$ years & $77(75 \%)$ & $26(25 \%)$ & $103(27 \%)$ & \\
\hline \multicolumn{4}{|l|}{ Gender } & \multirow[b]{3}{*}{0.399} \\
\hline Female & $106(63.4 \%)$ & $61(36.6 \%)$ & $167(43.6 \%)$ & \\
\hline Male & $146(67.5 \%)$ & $70(32.5 \%)$ & $216(56.4 \%)$ & \\
\hline \multicolumn{4}{|l|}{ Duration } & \multirow[b]{3}{*}{0.291} \\
\hline$<3$ years & $90(62.5 \%)$ & $54(37.5 \%)$ & $144(37.5 \%)$ & \\
\hline$\geq 3$ years & $162(68 \%)$ & $77(22 \%)$ & $239(62.5 \%)$ & \\
\hline \multicolumn{4}{|l|}{ Hypertension } & \multirow[b]{3}{*}{0.133} \\
\hline Non Hypertensive & $151(68.9 \%)$ & $68(31.1 \%)$ & $219(57.1 \%)$ & \\
\hline Hypertensive & $101(61.5 \%)$ & $63(38.5 \%)$ & $164(42.9 \%)$ & \\
\hline \multicolumn{4}{|l|}{ Liver Cirrhosis } & \multirow[b]{3}{*}{0.002} \\
\hline Absent & $114(75 \%)$ & $38(25 \%)$ & $152(39.6 \%)$ & \\
\hline Present & $138(59.7 \%)$ & $93(40.3 \%)$ & $231(60.4 \%)$ & \\
\hline \multicolumn{4}{|c|}{ Interferon Treatment } & \multirow[b]{3}{*}{0.004} \\
\hline No & $156(60.9 \%)$ & $100(39.1 \%)$ & $256(66.8 \%)$ & \\
\hline Yes & $96(75.6 \%)$ & $31(24.4 \%)$ & $127(33.2 \%)$ & \\
\hline
\end{tabular}


Frequency of Carotid Atherosclerosis in Hepatitis C Virus Positive Patients

\begin{tabular}{|l|l|l|l|}
\hline Family History & & & \\
\hline No & $137(63.4 \%)$ & $79(36.6 \%)$ & $216(56.4 \%)$ \\
\hline \multicolumn{1}{|c|}{ Yes } & $115(68.8 \%)$ & $52(31.2 \%)$ & $167(43.6 \%)$ \\
\hline Diabetes Mellitus & & & \\
\hline Absent & $105(76.6 \%)$ & $32(23.4 \%)$ & $137(35.7 \%)$ \\
\hline Present & $147(60 \%)$ & $99(40 \%)$ & $246(64.3 \%)$ \\
\hline Body Mass Index & & & \\
\hline$<25 k g / \mathbf{m}^{2}$ & $89(74.8 \%)$ & $30(25.2 \%)$ & $119(31.1 \%)$ \\
\hline$\geq \mathbf{2 5 k g} / \mathbf{m}^{2}$ & $163(61.7 \%)$ & $101(38.3 \%)$ & $264(68.9 \%)$ \\
\hline Total & $252(65.8 \%)$ & $131(34.2 \%)$ & $383(100 \%)$ \\
\hline
\end{tabular}

Out of the total 383 patients in our study, $164(42.82 \%)$ patients had hypertension and 219 $(57.18 \%)$ were not having hypertension (table 2).

Our study results showed that Liver Cirrhosis was present in $231(60.31 \%)$ patients and was absent in $152(39.69 \%)$ patients (table 2$)$.

In the study $127(33.16 \%)$ patients received interferon treatment and $256(66.84 \%)$ patients did not receive interferon treatment (table 2).

The study results showed that $167(43.6 \%)$ patients had a family history of atherosclerosis and 216 $(56.4 \%)$ patients had no family history of atherosclerosis (table 2).

Of the total 383 patients carotid atherosclerosis was present in $131(34.2 \%)$ patients and was absent in $252(65.8 \%)$ patients (table 2$)$.

Of the total 383 patients diabetes mellitus was present in $246(64.2 \%)$ patients and was absent in $137(35.8 \%)$ patients (table 2).

Mean BMI of total patients in the study was $29.64 \pm$ $6.64 \mathrm{~kg} / \mathrm{m}^{2}$ (table1). There were total $119(31.1 \%)$ patients of BMI $<25 \mathrm{~kg} / \mathrm{m}^{2}$, and $264(68.9 \%)$ patients of $\mathrm{BMI} \geq 25 \mathrm{~kg} / \mathrm{m}^{2}$ (table 1 ).

In Our study carotid atherosclerosis was present in 131 patients of whom 105 had age $<45$ years and 26 had age $\geq 45$ years. Statistically there is significant difference between the age of patient and presence of carotid atherosclerosis i.e. $\mathrm{p}$-value $<0.05$. This shows that carotid atherosclerosis is common in patients with age $<45$ years i.e., HCV positive patients have higher and early risk of developing carotid atherosclerosis (table 3).

There are 131 patients of carotid atherosclerosis of whom 70 were males and 61 were females. Statistically there is insignificant difference between the gender of patient and presence of carotid atherosclerosis i.e. p-value $>0.05$. This shows that gender has no impact in the development of carotid atherosclerosis in hepatitis $\mathrm{C}$ positive patients (table 3).

The study results showed that carotid atherosclerosis was present in 131 patients of whom 54 had hepatitis $\mathrm{C}$ virus infection for $<3$ years and 77 had hepatitis $\mathrm{C}$ virus infection for $\geq 3$ years. Statistically there is insignificant difference between the duration of hepatitis $\mathrm{C}$ and presence of carotid atherosclerosis i.e. p-value $>0.05$. This shows that duration of hepatitis $\mathrm{C}$ virus infection has no impact in the development of carotid atherosclerosis in hepatitis $\mathrm{C}$ positive patients (table 3).

\section{Comparison of Carotid Atherosclerosis with Hypertension:}

There are 131 patients of carotid atherosclerosis of whom 63 patients were hypertensive and 68 were non hypertensive. Statistically there is insignificant difference between the presence of carotid atherosclerosis and hypertension i.e. p-value $>0.05$. This shows that hypertension has no impact in the development of carotid atherosclerosis in hepatitis $\mathrm{C}$ positive patients (table 3 ).

\section{Comparison of Carotid Atherosclerosis with Liver Cirrhosis:}

In this study carotid atherosclerosis was present in 131 patients of whom liver cirrhosis was present in 93(71\%) patients and absent in 38(29\%) patients. Statistically there is significant difference between the occurrence of carotid atherosclerosis and presence of liver cirrhosis i.e. p-value $<0.05$. This shows that carotid atherosclerosis is common in patients with liver cirrhosis i.e., hepatitis $\mathrm{C}$ positive patients with liver cirrhosis have higher chances of developing carotid atherosclerosis (table 3 ).

\section{Comparison of Carotid Atherosclerosis with Interferon Treatment:}

The study results showed that carotid atherosclerosis was present in 131 patients of whom 31 had taken interferon treatment and 100 had not taken interferon treatment. Statistically there is insignificant difference between the presence of carotid atherosclerosis and interferon treatment i.e. p-value < 0.05 . This shows that carotid atherosclerosis is common in patients who have not taken interferon treatment i.e., interferon treatment reduces the incidence of carotid atherosclerosis in $\mathrm{HCV}$ positive patients (table 3 ). 
Comparison of Carotid Atherosclerosis with Family History of Atherosclerosis:

In this study carotid atherosclerosis was present in 131 patients of whom 93 patients had positive family history of atherosclerosis and 38 patients had no family history of atherosclerosis. Statistically there is insignificant difference between the presence of carotid atherosclerosis and family history of atherosclerosis i.e. p-value > 0.05 . Our p-value didn't come significant and it reveals that that family history of atherosclerosis has no impact in the development of carotid atherosclerosis in $\mathrm{HCV}$ positive patients (table 3 ).

\section{Comparison of Carotid Atherosclerosis with} Diabetes Mellitus:

In this study carotid atherosclerosis was present in 131 patients of whom diabetes mellitus was present in 99 patients and absent in 32 patients. Statistically there is significant difference between the occurrence of carotid atherosclerosis and presence of diabetes mellitus i.e. p-value $<0.05$. This shows that carotid atherosclerosis is common in patients with diabetes mellitus i.e., hepatitis $\mathrm{C}$ positive patients with diabetes have higher chances of developing carotid atherosclerosis and so the stroke (table 3 ).

\section{Comparison of Carotid Atherosclerosis with Body Mass Index:}

In this study carotid atherosclerosis was present in 131 patients of whom 30 patients had BMI $<25 \mathrm{~kg} / \mathrm{m}^{2}$ and 101 patients had BMI $\geq 25 \mathrm{~kg} / \mathrm{m}^{2}$. Statistically there is significant difference between the occurrence of carotid atherosclerosis and BMI i.e. p-value < 0.05 . This shows that carotid atherosclerosis is common in patients with BMI $\geq 25 \mathrm{~kg} / \mathrm{m}^{2}$ i.e., hepatitis $\mathrm{C}$ positive patients with raised BMI have higher chances of developing carotid atherosclerosis (table 3).

\section{Discussion:}

Since Pakistan is an HCV endemic area with second highest prevalence rate of $4-8 \%$ the need was even greater to determine the prevalence of carotid atherosclerosis among $\mathrm{HCV}$ positive patients presenting to the inpatient and outpatient department of Sir Ganga Ram Hospital, Lahore. The purpose of this study was to identify patients at risk of disabling cerebrovascular disease at an earlier stage and plan and initiate treatment accordingly so that burden of disease could be reduced. Carotid atherosclerosis was defined as intima media thickness of $>0.8 \mathrm{~mm}$ on Doppler ultrasound study. The frequency of carotid atherosclerosis in our study was $34.2 \%$ which is quite high. Patients already having dyslipidemia and TIA or history of stroke were excluded from the study in attempt to remove the confounders.

Cerebrovascular disease is the second leading cause of mortality worldwide and is the leading cause of serious long term disability in the United States. ${ }^{5}$

Traditional risk factors for stroke like cigarette smoking, hypertension, diabetes, obesity, hyperlipidemia and alcohol are unable to completely account for the risk of atherosclerosis. It has convincingly emerged that inflammation is the hallmark of atherosclerosis, the main underlying pathology in cerebrovascular disease. Inflammation is often triggered by infectious agents and hepatitis C is implicated as one of the infectious viral agent.

HCV patients showed a higher level of inflammation $\&$ accelerated atherosclerosis. ${ }^{6}$ The virus replicates in carotid plaques so $\mathrm{HCV}$ positive patients have a higher \& early risk of Stroke \& Coronary Artery Disease ${ }^{7}$ Chronic HCV infection increases the risk of ultrasonographically defined carotid plaques or carotid intima-media thickness which predispose to cerebrovascular disease. ${ }^{6,7}$ Serum HCV-RNA level indicates active $\mathrm{HCV}$ replication \& HCV genotype determines liver disease severity. ${ }^{14}$

One Study conducted by Petta, et $\mathrm{al}^{15}$ Concluded that Carotid plaques prevalence is $41.9 \%$ in chronic $\mathrm{HCV}$ patients as compared to controls $22.9 \% .^{15}$ However our study showed $34.2 \%$ prevalence which is comparable with the study conducted by Petta, et $\mathrm{al}^{15}$ that minor difference can be attributed to that fact that Petta, et $\mathrm{al}^{15}$ also had a control group for comparison and we didn't have the control group

Another study showed higher prevalence of Carotid Atherosclerosis $53.7 \%$ as compared to controls. ${ }^{13}$

A recent study conducted by Osama A, et al. ${ }^{16}$ in December 2019; found that intima-media thickness $>1 \mathrm{~mm}$ was significantly associated and more frequent with $(80 \%) \mathrm{HCV}$ positive patients and in our study $34.2 \%$ had carotid atherosclerosis and this difference can be attributed to the fact that Study Conducted by Osama $\mathrm{A}$, et $\mathrm{al}^{16}$ took both $\mathrm{HCV}$ positive and $\mathrm{HCV}$ negative patients and sample size was 100 only, in contrast to our study we had 383 patients and all had chronic HCV infection.

Another study conducted by Boddi $\mathrm{M}^{17}$ and colleagues revealed that intima media thickness $(\mathrm{IMT})>1 \mathrm{~mm}$ was strongly linked with Anti-HCV positive patients. $28(90 \%)$ patients having $\mathrm{HCV}$ 
positivity had IMT of $>1 \mathrm{~mm}$ and significant carotid atherosclerosis, in contrast to our study, 131 (34.2\%) and significant carotid atherosclerosis, this difference can be explained on the basis of our larger sample size with no control group and Boddi and Colleagues had smaller number of $\mathrm{HCV}$ positive patients with control group as well.

A study conducted by Lee $\mathrm{MH}$, et al. ${ }^{18}$ showed that Chronic HCV is an independent risk factor for stroke related deaths by accelerated atherosclerosis in these patients with high viremia as well and in contrast to our study we only looked for the carotid atherosclerosis and predicted the stroke risk but we didn't perform the HCV ribonucleic acid (RNA) polymerase chain reaction (PCR).

A study conducted by Liao $\mathrm{CC}^{19}$ and colleagues concluded that $\mathrm{HCV}$ positive patients were at higher risk of developing stroke as our study showed that $34.2 \%$ patients had carotid atherosclerosis and were at higher risk of stroke.

A study conducted by Barakat AA, et $\mathrm{al}^{20}$ concluded that higher values of IMT were observed in $\mathrm{HCV}$ patients and more in patients with cirrhosis than patients not having cirrhosis, In contrast to our study $71 \%$ patients had carotid atherosclerosis with cirrhosis in our $\mathrm{HCV}$ positive patients which is highly significant.

One Study conducted by Petta, et al. ${ }^{15}$ Concluded that the mean BMI of the participants was $26.2 \pm 4.6$ $\mathrm{kg} / \mathrm{m}^{2}$ and in our study it was $29.64 \pm 6.64 \mathrm{~kg} / \mathrm{m}^{2}$ which is comparable. Which means most of the patients were falling in above normal BMI category and adding on $\mathrm{HCV}$ infection related carotid atherosclerosis.

Petta $^{15}$ and colleagues found out of 73 patients who had carotid plaques; $15 \mathrm{HCV}$ patients were hypertensive and 6 patients were having diabetes and in contrast to our study, we had 63 hypertensive patients and 99 patients were having diabetes, these differences can be attributed to that our all patients had HCV positive status with a larger sample size with the above mentioned study.

\section{Conclusion:}

There were quite a number of HCV positive patients who were found to have carotid atherosclerosis which is quite alarming. We also observed that prevalence was related to age, interferon treatment and liver cirrhosis. Younger age group was affected in majority. Patients who had taken interferon treatment had decreased prevalence of carotid atherosclerosis. The presence of liver cirrhosis and diabetes mellitus increased the incidence of carotid atherosclerosis. Overweight and obese individuals with $\mathrm{HCV}$ infection were adversely affected.

\section{Limitations:}

Our study was single centre with relatively smaller sample size, and we didn't have any control group, so results cannot be generalized to whole population of the country.

\section{Recommendations:}

The prevalence rate stresses the need for screening of patients with $\mathrm{HCV}$ for carotid atherosclerosis with non invasive imaging. This would help in early diagnosis and thus early institution of treatment for patients thus avoiding disabling cerebrovascular disease.It is strongly recommended on the basis of results of our study to screen noninvasively via carotid Doppler which is quick, easy, accessible, easily available and convenient way of assessing for atherosclerosis in all patients with chronic HCV infection. Knowledge of the whole pathologic burden will be of great help in making a sound decision for the management of chronic HCV infection. Multicenter studies with larger sample sizes across the country with HCV-RNA PCR be done to see the effect of viremia/viral load on atherosclerosis as done in many recently conducted studies.

Lastly, while decision making, researchers and clinicians should take these new findings into their consideration for better outcomes.

\section{References}

1. Infectious diseases related to travel. Centers for disease control and prevention. http://wwwnc.cdc.gov/travel/yellowbook/2014/chapter-3infectious-diseases-related-to-travel/hepatitis-c

2. Jiwani N, Gul R. A Silent Storm: Hepatitis $\mathrm{C}$ in Pakistan.JPMC. 2011;1(3).DOI

https://doi.org/10.26634/jnur.1.4.1531

3. Wawrzynowicz-Syczewska M. Late sequelae of HCV infection. PrzeglEpidemiol. 2008; 62(4):777-83.

4. Galossi A, Guarisco R, Bellis L, Puoti C. Extrahepatic manifestations of chronic HCV infection Gastrointestin Liver Dis. Mar 2007; 16(1):65-73.

5. Murray CJL, Lopez AD. Mortality by cause for eight regions of the world: global burden of disease study. Lancet. 1997; 349: 1269-1276. https://doi.org/10.1016/s01406736(96)07493-4

6. Akhtar B, Hanif A, Qureshi N, Hussain S, Siddique K, et al. Hepatitis C virus (HCV) "A possible Independent Risk Factor " for coronary Artery Disease. Annuals of king Edward medical University. 2010;16(3):

7. Adinolfi LE, Restivo L, Guerrera B, Sellitto A, Ciervo A, et al. Chronic HCV infection is a risk factor of ischemic stroke. $\begin{array}{lll}\text { Atherosclerosis. } & \text { Nov 2013;231(1):22-6. }\end{array}$ https://doi.org/10.1016/j.atherosclerosis.2013.08.003

8. Morgan RL, Baack B, Smith BD, Yartel A, Pitasi M, FalckYtter Y. Eradication of Hepatitis C Virus Infection and the 
Development of Hepatocellular Carcinoma: A Meta-analysis of Observational Studies. Annals of Internal Medicine. Mar 2013. 158 (5 Pt 1): 329-37.https://doi.org/10.7326/00034819-158-5-201303050-00005.

9. Gravitz L. A smouldering public-health crisis. Nature. 2011; 474 (7350): S2-4. https://doi.org/10.1038/474s2a .

10. Mohd Hanafiah K, Groeger J, Flaxman AD, Wiersma ST. Global epidemiology of hepatitis $C$ virus infection: new estimates of age-specific antibody to $\mathrm{HCV}$ seroprevalence. Hepatology (Baltimore, Md.). Apr 2013. 57 (4): 1333-42. https://doi.org/10.1002/hep.26141.

11. Costantini S, Capone F, Guerriero E, Maio P, Colonna G, Castello G. Serum cytokine levels as putative prognostic markers in the progression of chronic HCV hepatitis to cirrhosis. Eur Cytokine Netw.2010; 21: 251-256.

12. Oliveira CP, Kappel CR, Siqueira ER, Lima VM, Stefano JT, Michalczuk MT, Marini SS, Barbeiro HV, Soriano FG, Carrilho FJ, et al. Effects of hepatitis $\mathrm{C}$ virus on cardiovascular risk in infected patients: a comparative study. Int J Cardiol. 2013; 164: 221-226. https://doi.org/10.1016/j.ijcard.2011.07.016.

13. Adinolfi LE, Restivo L, Zampino R, Guerrera B, Lonardo A, et al. Chronic HCV infection is a risk of atherosclerosis. Role of $\mathrm{HCV} \& \mathrm{HCV}$ - related steatosis. Atherosclerosis. Apr 2012; 221(2):496-502. https://doi.org/10.1016/j.atherosclerosis.2012.01.051.

14. Bruno S, Crosignani A, Maisonneuve P, Rossi S, Silini E, et al. Hepatitis $\mathrm{C}$ virus genotype $1 \mathrm{~b}$ as a major risk factor associated with hepatocellular carcinoma in patients with cirrhosis: a seventeen-year prospective cohort study. Hepatology. 2007; 46: 1350-1356. https://doi.org/10.1002/hep.21826.
15. Petta S, Torres D, Fazio G, Camma C, Cabibi D, Di Marco $\mathrm{V}$, et al. Carotid atherosclerosis and chronic hepatitis $\mathrm{C}$ : a prospective study of risk associations. Hepatology. 2012 May; 55(5):1317-23.https://doi.org/10.1002/hep.25508.

16. Osama A, Ashour Y, Abd El-Razek R, Monir D. Assessment of carotid intima-media thickness and carotid plaque formation among patients with ischemic stroke and hepatitis $C$ virus infection. The Egyptian Journal of Neurology, Psychiatry and Neurosurgery. 2019 Dec 1;55(1):6 https://doi.org/10.1186/s41983-019-0054-2.

17. Boddi M, Abbate R, Chellini B, Giusti B, Solazzo V, et al. $\mathrm{HCV}$ infection facilitates asymptomatic carotid atherosclerosis: preliminary report of HCV RNA localization in human carotid plaques. Digestive and Liver Disease. 2007 Sep 1;39:S55-60.https://doi.org/10.1016/s15908658(07)80012-0.

18. Lee $\mathrm{MH}$, Yang $\mathrm{HI}$, Wang $\mathrm{CH}$, Jen $\mathrm{CL}$, Yeh $\mathrm{SH}$, et al.Hepatitis $\mathrm{C}$ virus infection and increased risk of cerebrovascular disease. Stroke. 2010 Dec 1;41(12):2894900. https://doi.org/10.1161/strokeaha.110.598136.

19. Liao CC, Su TC, Sung FC, Chou WH, Chen TL. Does hepatitis $\mathrm{C}$ virus infection increase risk for stroke? A population-based cohort study. PloS one. 2012 Feb 20;7(2):e31527. https://doi.org/10.1371/journal.pone.0031527.

20. Barakat AA, Nasr FM, Metwaly AA, Morsy S, Eldamarawy M. Atherosclerosis in chronic hepatitis $\mathrm{C}$ virus patients with and without liver cirrhosis. The Egyptian Heart Journal. 2017 Jun $1 ; 69(2): 139-47$. 